\title{
Application of Blockchain Technology in Agricultural Products' Traceability System
}

\author{
Hai-Shui Yan ${ }^{1}$, Jun-Won Yang ${ }^{2}$, Hyung-Ho Kim³ \\ ${ }^{1}$ Doctoral Student, Graduate School of Business, Sehan University, Korea, yanhaishui@ gmail.com \\ ${ }^{2}$ Professor, Dept. of Air Transport and Logistics, Sehan University, Korea, jwyang@sehan.ac.kr \\ ${ }^{3}$ Professor, Dept. of Air Transport and Logistics, Sehan University, Korea, hhkim@sehan.ac.kr
}

Corresponding author: Hyung-Ho Kim

\begin{abstract}
Nowadays, many consumers pursue a healthy and safe diets through green food or organic agricultural products. However, due to the development of the Internet and the frequent occurrence of various food safety incidents, people often do not trust ecological organic agricultural products thinking they are not genuine. In this context, the traceability of agricultural products is particularly important. At the same time, the current popular blockchain technology has gradually penetrated our daily lives after more than ten years of development and application. There are a large number of regional blockchain applications integrated into life from the world level, national level and industry development level.The blockchain is convenient and safe, and it is decentralized and has information security. Therefore, applying application of blockchain technology in the traceability system of agricultural products industry can bring great trust value to the whole agricultural ecological products, and can effectively promote the relationship between farmers and consumers. The characteristics of blockchain mainly include decentralization, immutability of information, openness, and autonomy. These characteristics are the main reasons for the widespread promotion of blockchain. The entire system is maintained by data blocks in the system, using distributed data storage, no centralized storage mechanism and centralized management mechanism troubles, any node is equal, and each node has the key to the correctness of the record result. Once the information is stored, it will be permanently stored in the block. This paper reviews the history of the formation and development of agricultural traceability systems in major foreign and domestic countries agricultural traceability systems, and puts forward the viewpoint of combining blockchain technology with agricultural traceability systems. This article adopt qualitative research method and case study method, through indepth research and analysis of representative blockchain application cases in the field of agricultural traceability, Finally, through the research and analysis of this article, it can be concluded that the application of blockchain and Iot technology in the agricultural traceability system has two effects. Furthermore, it provides suggestions on the application and development of blockchain technology in the domestic agricultural traceability system, hoping to provide useful references for promoting the indepth development of blockchain technology in the agricultural field.
\end{abstract}

Keywords: Blockchain, Agricultural Product, Traceability System, Application

\section{Introduction}

\subsection{Theoretical Introduction and Development Research of Blockchain Technology}

Blockchain, also known as distributed ledger, is a distributed accounting technology and a

Received: July 10, 2021; $1^{\text {st }}$ Review Result: August 26, 2021; $2^{\text {nd }}$ Review Result: October 12, 2021

Accepted: November 30, 2021 
distributed database system involving nodes. It is composed of six parts: application layer module,contract layer module,incentive layer module,consensus layer module,network layer module and data layer module [Fig. 1]. Based on the principle of the minority obeying the majority, the algorithm (consensus model) is used to provide a trusted environment to make sure the nodes' data exchange process and the exchange history record shall not be tampered with. Blockchain technology originated from database, P2P network technology, asymmetric encryption algorithm, digital currency and other technologies[1]. It is an innovative combination of original information technology. The digital currency represented by Bitcoin is developing rapidly. Experts in various fields have seen the unlimited potential of the blockchain as the underlying technology and infrastructure of Bitcoin. The most important features of blockchain technology include decentralization, openness, autonomy, anonymity, information that cannot be tampered with, and information traceability. The formation of these features is related to the working principle behind blockchain technology[2]. In a nutshell, the blockchain adopts distributed accounting and storage, all entities can participate in the recording of information, and there is no need for centralized server hardwares or management organization institutions. This is the reason for decentralization and openness; the blockchain is based on consensus open source and transparent algorithms created by the mechanism. The work of exchanging data between nodes follows a fixed and consentient algorithm. This is the reason for the formation of autonomy and anonymity; the working principle of the blockchain technology linkage mechanism is to set the next block associate the hash value of the previous block, only when the previous hash value is identified, can it be connected. If the hash value of a block is changed, you must continue to modify the content of all subsequent blocks in turn to ensure The information can be traced and cannot be tampered with.

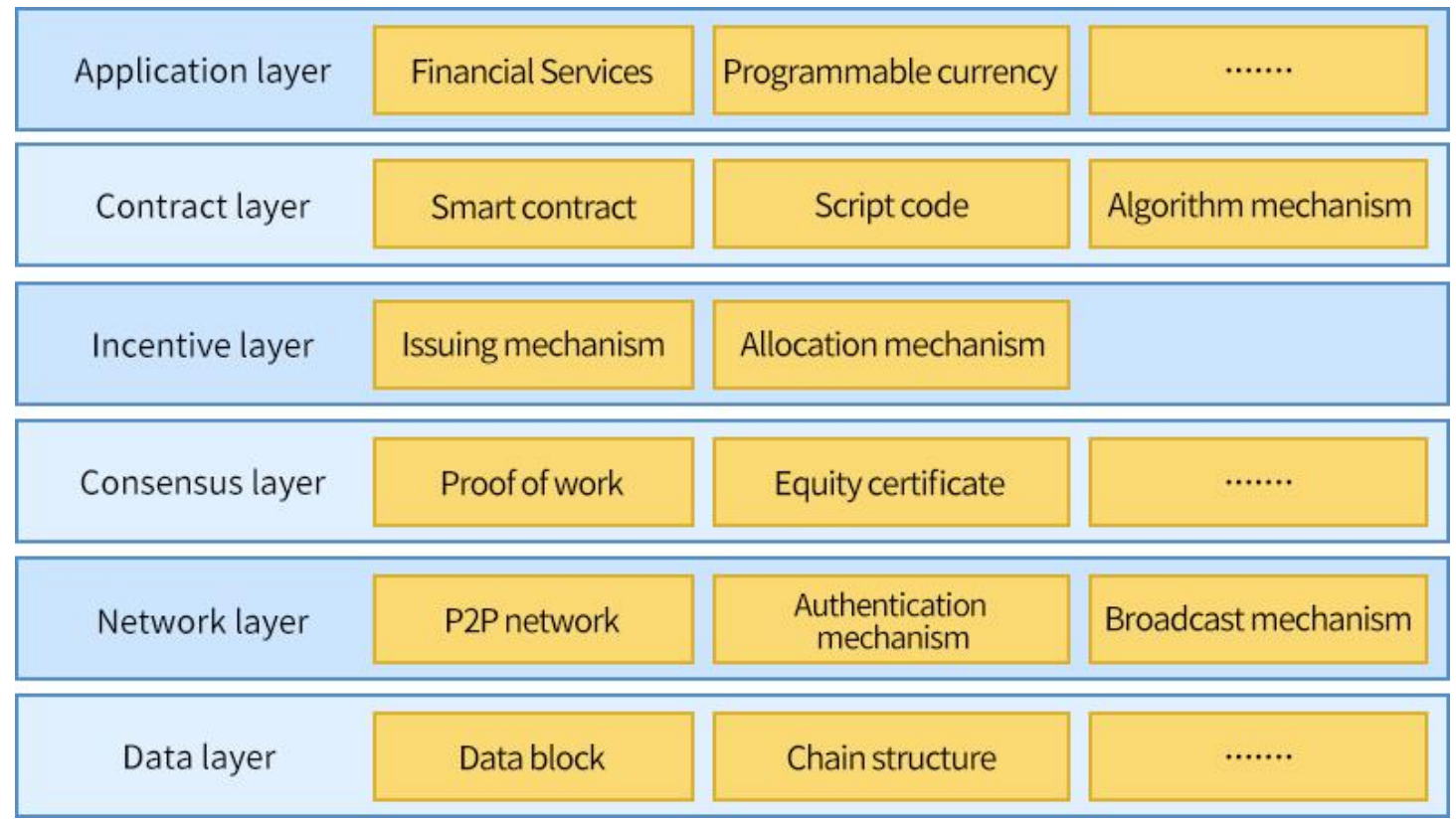

[Fig. 1] Blockchain Infrastructure Model

\subsection{The Development and Application Trend of Blockchain}

After 12 years of rapid development, blockchain technology has been well known by the general public all over the world and applied in various industries. As the key technology of the next generation of Internet, blockchain has always been the key layout target of governments and giant 
enterprises[3]. The blockchain technology has achieved varying degrees of application in various fields such as finance, government affairs, medical care, and industrial manufacturing in the global field, and the society's understanding of the value and applicable scenarios of the blockchain has been continuously improved. After a special meeting of China leaders on blockchain technology on October 24,2019 , cities in all industries and across the country ushered in the spring of blockchain application exploration and development, and the blockchain officially began to enter a rapid development. In the agricultural industry, the Central Committee in 2020 issued that the blockchain will vigorously promote and strengthen the construction of modern agricultural facilities, depend on existing resources to establish agricultural and rural big data centers, and promote the artificial intelligence(AI), blockchain technology, Internet of Things(Iot), big data and the application of current information technologies includes modern mobile communication networks and smart weather in the agricultural field[4]. The traceability system of agricultural products industry based on blockchain technology is the latest development and application stage of the current traceability system, which can bring brandnew rules and trust value. It uses blockchain technology to realize distributed accounting, create basic services such as identity recognition and credit management. realizes business reengineering. In the past,as a result of to the lack of transparency and government supervision in the production and circulation links of the agricultural product industry chain, problems such as food safety, counterfeit and inferior products, and loss and damage of goods have emerged one after another, causing consumer rights issues and damaged interests[5]. Blockchain technology can effectively make up for and improve the shortcomings of existing commodity traceability technology, Realize whole process control, provide real-time evidence collection, increase transparency, prevent counterfeiting and improve consumer trust.

\subsection{The Importance of the Combination of Blockchain and Agricultural Traceability System}

Blockchain technology has a series of unique advantages. This makes the traceability system that integrates blockchain technology better than the previous traceability system in data entry, storage, protection, and query [Table 1]. Compared with the agricultural product traceability system based on traditional internet technology in the past, the traceability system based on blockchain technology does not bring obvious differences in the user experience during the use of the product, and the main difference lies in the back-end[6]. The difference in the back-end is that blockchain technology can provide new traceability tools to facilitate consumers' inquiries on agricultural product safety information. In addition, the blockchain has the characteristics of decentralization, and all nodes can share data in real time through the chain, and all nodes must also perform the obligation of jointly maintaining the reliability of data. Compared with the two, the agricultural traceability system using blockchain technology has more obvious advantages than the traditional traceability system. For example, it breaks through the information barriers, improves the system's deficiencies, and ensures the stability, security, and transparency of data, and it is convenient for comparison. Timely control of data and improved technology also provide a network platform that allows all parties to interact with information and data. In the agricultural product quality and safety management system, the agricultural product traceability system based on blockchain and Iot technology is crucial. It connects all links in the supply chain such as product production, product processing, product circulation, product storage, and product sales, and digitally records and manages product information. For all the information, a transparent and accurate agricultural product data information database has been established so that the information can be accurately, completely and timely transported and communicated in all links of the supply chain. Therefore, consumers, buyers, sellers and relevant departments can quickly inquire all the information about the products in the supply chain. Once there is a problem in any link, consumers or management can quickly find the problem through the 
traceability system and traceability information, and it can be resolved as soon as possible by means of recall or control, effectively preventing sudden food safety incidents, preventing large-scale food safety incidents, and ensuring agricultural product quality control and food safety protect the legitimate rights of consumers from the source, and to provide supervision and decision-making basis for the regulatory authorities. It also allows us to fully see how blockchain technology empowers the agricultural traceability product system and how to reconstruct the traceability process of the entire industry. Bring a new experience to government regulatory agencies, upstream and downstream industries, and end consumers.

[Table 1] Comparison of Traditional Traceability and Blockchain Traceability

\begin{tabular}{|c|c|c|}
\hline Difference & Tradition & Blockchain traceability \\
\hline Front end & $\begin{array}{l}\text { Use various network sensors, information } \\
\text { collection terminals and other equipment to } \\
\text { complete data collection }\end{array}$ & $\begin{array}{l}\text { Not much different from traditional } \\
\text { traceability }\end{array}$ \\
\hline Rear end & $\begin{array}{l}\text { The source is traced according to the anti- } \\
\text { counterfeiting code produced by the } \\
\text { merchant, but this anti-counterfeiting mark } \\
\text { is made by the merchant with pre-edited } \\
\text { data, which is easy to be copied on a large } \\
\text { scale }\end{array}$ & $\begin{array}{l}\text { Blockchain provides new tools for } \\
\text { traceability business. Consumers can use } \\
\text { RFID chips or QR codes, barcodes, etc. on } \\
\text { agricultural products to inquire about the } \\
\text { production location, picking time, use of } \\
\text { medical fertilizers, storage and } \\
\text { transportation information, etc. }\end{array}$ \\
\hline $\begin{array}{l}\text { Information cannot be } \\
\text { tampered with }\end{array}$ & $\begin{array}{l}\text { Centralized storage mode, data can easily } \\
\text { be tampered with by authorized parties }\end{array}$ & $\begin{array}{l}\text { Digital input method reduces manual } \\
\text { participation and protects data from being } \\
\text { tampered with }\end{array}$ \\
\hline Safety & $\begin{array}{c}\text { Centralized storage mode, data is } \\
\text { vulnerable to attack }\end{array}$ & $\begin{array}{l}\text { In a distributed environment, any node } \\
\text { failure will not affect the stability, security } \\
\text { and normal operation of the whole system }\end{array}$ \\
\hline Transparency & $\begin{array}{l}\text { Only the results, without showing the } \\
\text { process, the data is not transparent and true } \\
\text { enough }\end{array}$ & $\begin{array}{l}\text { Data will be automatically recorded } \\
\text { throughout the entire process from input, } \\
\text { modification to final confirmation, ensuring } \\
\text { a high degree of transparency and } \\
\text { truthfulness of the data }\end{array}$ \\
\hline Autonomy & $\begin{array}{l}\text { Highly dependent on central institutions, } \\
\text { poor autonomy }\end{array}$ & $\begin{array}{l}\text { Using algorithms created based on the } \\
\text { consensus mechanism, "people" have trust } \\
\text { in the machine, eliminating the interference } \\
\text { of human factors, and achieving a high } \\
\text { degree of autonomy }\end{array}$ \\
\hline
\end{tabular}

\section{Contents}

\subsection{Problems in the Traceability of Traditional Agricultural Products}

From the perspective of the current composition of the traditional traceability system for agricultural products, on one hand, there are many links in the entire industrial chain, and each link usually contains its own sub-links, which is long and complex; on the other hand, the industrial chain has many participants[7]. Specifically, the current agricultural product traceability system mainly has the following problems:

1) The asymmetry of information among the participating entities leads to unbalanced production and sales. The entire agricultural product industry chain is long and complex, and various types of information are scattered and stored in different links. Since the participating entities have simple buying and selling relationships with each other, they have not established trust relationships with each other. In order to protect their own interests and ensure information security, the participating entities are usually unwilling to share information. Therefore, agricultural producers do not make reasonable 
production based on market demand, and distributors do not make reasonable purchases as well. They usually use their own subjective will based on production and procurement, resulting in an imbalance between production, supply and marketing.

2) The asymmetry of information among the participating entities has resulted in inefficient operation of the entire agricultural product chain. The entire agricultural product chain has many links and many participants. The participants are carrying out complex multi-stream cooperation. However, due to the information asymmetry among the participating entities, the business flow, information flow, logistics and capital flow generated by each other cannot be realized. To circulate credibly, the management cost of the entire agricultural product chain is high, which leads to low operating efficiency.

3) In real life, the proportion of consumers who scan code to verify products is not high, and consumers do not have a high degree of trust in traceability information. This is due to the lack of credibility in traditional traceability. In other words, most traceability systems in China are centralized systems established by companies to increase user trust, but there are too many possibilities in this system to be tampered with by individuals or companies themselves. Thus losing transparency and credibility. At the same time, the information that consumers can find through traditional traceability channels is limited to regular information such as brand, name, specification, standard number, and shelf life, and key information such as product source and logistics is not displayed.

4) Traceability is applied in various industries, but because of different industries, the supply chain management is also different, so that there is no unified standard in the traceability process. At the same time, different traceability management systems are used in various regions, resulting in the inability to interact with the data between the systems and becoming an isolated island of information, leading to a waste of resources. Not only is it vulnerable to hacker attacks and data loss, but there is also a phenomenon of data distortion caused by artificial tampering. Occurrence also limits the development of traceability industry.

5) The information storage of the current traceability system often uses a single database for centralized storage, which causes the fraudulent party to tamper with the database, thereby achieving the purpose of increasing and reducing the fraudulent products. Even if redundant database backups are used, counterfeiters can achieve their goals by tampering with redundant databases, and it's difficult to identify false data.

6) Multi-point information recording and reconciliation efficiency is low. In the current traceability system, when goods are transferred from one point to another (such as a manufacturer to a logistics company), both parties have their own information records (such as manufacturer production records, logistics company logistics records), etc. These information records need to be reconciled period. Separate input and other operations, when traceability information appears asymmetry, a lot of manual traceability is required, which is low in efficiency.

7) The traceable barcode is reproducible. In the current traceability system, most of the twodimensional codes, barcodes, etc. are used for one-object-one-code correspondence, and these barcodes are reproducible, which makes the product traceability invalid.

\subsection{The Relationship between Blockchain Technology and Agricultural Development}

At this stage, the overall development of China agriculture has become a slow development trend. The export of agricultural cash crops has continued to grow, the amount of grain storage has increased, the decline in domestic agricultural product prices has further narrowed, the sales of terminal foods have basically stabilized, and the growth of agricultural investment has continued to slow down period. Expenditure on agriculture rose slightly year-on-year, and the growth rate of farmers' average income slowed down[8]. China agriculture is still in a relatively backward and crude economic model, and the level of informatization and modernization is still in its infancy. It is necessary to introduce 
more advanced technologies to improve the level of agricultural intelligence. Therefore, in the development of the agricultural economy, modern technology and network technology will surely be boosted. From the perspective of blockchain technology, there are several points that can be injected to provide fresh blood to the agricultural economy. First of all, it should be able to control from the source, improve the quality of crops, improve the quality of products, rely to blockchain technology to use decentralization node consensus algorithms to manager and save data, record the data records of crop products from planting to growth, and improve the growth data. There should be data sharing to analyze and transmit, share data, and improve crop yields and crop varieties according to local conditions. Regarding the issue of crop safety, people should eat at ease. Based on the blockchain technology, the agricultural products and technology transmission equipment, soil analysis, water quality analysis, and agricultural product data are automatically transmitted to the chain and uploaded to the blockchain. Blockchain cannot only reduce transaction costs, but more importantly, it can reenergize the agricultural industry. At present, China's agricultural big data has made great progress, but its foundation is still relatively weak, especially the data on agricultural and rural areas are scattered and cannot be effectively integrated. In this regard, there is an urgent need for a big data platform to integrate, so as to gradually realize the digitalization and electronicization of the entire agricultural industry chain, and finally form valuable agricultural big data, which can be applied to agricultural industry scenarios. As a platform, blockchain is connected to big data at one end, and through the cleaning of data sources, it provides "raw materials" for algorithms to achieve deep learning and analysis and calculation, and provides basic conditions for the digitalization of the agricultural industry; at the other end, it connects to intelligent systems to enable IoT technology and intelligence. The construction of equipment and industry data standards has operational conditions. In other words, if big data is the means of production and artificial intelligence and other algorithms are productivity, then the blockchain is the production relationship. The role of blockchain in driving the transformation and upgrading of the agricultural industry is becoming more and more obvious, and the transformation trend of agricultural and rural production models it leads will inevitably accelerate. The huge momentum generated by new business formats and new scenarios will become an important force to promote the implementation of the rural revitalization strategy[9].

\subsection{Research Status of Domestic and Foreign Blockchain Technology in the Field of Traceability of Agricultural Products}

Researchers at home and abroad are not only actively exploring the role of blockchain technology in promoting data sharing, ensuring information integrity, and traceability, but also the impact of blockchain on the operation of agricultural traceability systems and the impact on institutional management capabilities, etc. Research has been carried out on various topics. provenance is the first company to use blockchain technology to provide full traceability for products in the supply chain. It tracks the entire life cycle of the product. There are various products in the supply chain. Application research in the agricultural field is carried out. There was a study on the pilot project of tuna certification based on blockchain technology[10], using supply chain technology to realize the transparency and traceability of data information in the supply chain. Mature technology company use information technologies such as blockchain and the Internet of Things in their asset management systems. The Internet of Things technology is used to track the entire process of crops from planting, transportation to sales. The content recorded through blockchain technology is very detailed. And to be specific, ensure that the data cannot be tampered with. Including changes in crop appearance, color and maturity, each product has a detailed record. In the new asset management system, the credibility, integrity, and sharing of data information have been greatly changed and improved compared with the previous ones, and will be more reliable. The management model of distributed accounting to ensure 
the authenticity and credibility of data also provides new development ideas for other farm managers. Skuchain company applies blockchain technology to the tracking link of the entire product circulation, and uses blockchain technology to track the entire circulation process of agricultural products, thereby strengthening the record and supervision of the product supply chain. By adopting the distributed accounting method, and through the form of data opening and sharing, users can query detailed information about the production date and production status of the purchased agricultural products anytime and anywhere. The integrity and transparency of data information in the supply chain provide a solid and credible foundation for the traceability of information. IBM cooperates with domestic and foreign research institutions such as Wal-Mart and Tsinghua University to use blockchain for food traceability systems. The blockchain authenticates each product and keeps open and transparent product records. In the same year, they proposed an agricultural supply chain public chain system based on a double-chain structure in response to some key problems existing in the current domestic public service platform [11]. Blockchain system, and in-depth study of this double-chain structure and its storage mode is needed. Practical results show that the agricultural product supply chain based on the dual-chain structure can ensure the openness and security of transaction information, while also effectively guaranteeing privacy and security, and efficiently completing tasks such as resource matching, thus increasing the public's trust in the public service platform, and proving that blockchain technology has huge application potential in the field of public utilities, or it can be applied to more large-scale fields. It also proposed a blockchain double-chain structure-a blockchain-plus-chain data structure[12]. Under the double-chain storage structure, the chain data structure is used to save the blockchain transaction hash value, which effectively guarantees the information security of agricultural products and prevents them from being maliciously tampered with or destroyed. In 2020, they took Liu Minying Ecological Farm in Beijing as an example to establish a blockchain-based eagriculture framework[13]. Under this framework, the blockchain network uses various smart devices to automatically complete the work of collecting and uploading data, which solves the problems of information asymmetry of third-party institutions and poor food traceability, while also expanding the shareable information set.In addition, they introduced the idea of integrating blockchain technology into the traditional fish farm system to establish a blockchain-based fish farm platform[14]. Blockchain technology is not only effective in promoting data sharing and ensuring the integrity of information, but also has a certain effect on improving the operation effect of the agricultural traceability system, improving the management capabilities of the organization, and innovating business models. In 2019, they researched the agricultural product safety traceability system based on blockchain technology, compared the "blockchain + agriculture" food safety traceability system with the traditional traceability system[15], and summarized the advantages brought by the use of blockchain technology, including effectively reducing data storage costs, supervision costs, improving operational efficiency, expanding financing paths, etc., and also analyzing in detail the obstacles that the system needs to overcome in the future development, such as the urgent need to expand the talent team and the relevant laws and regulations to be improved.

\subsection{The Development History of Agricultural Product Traceability and How to Integrate with Blockchain Technology}

In the 1970s, a severe mad cow disease broke out in Europe, and the establishment of a traceability system for the safety and quality of agricultural products originated from this. The first traced products were mainly livestock products such as beef and mutton. In 2000, the mad cow disease crisis broke out again in Europe. The European Union took the lead in formulating an agricultural product traceability system, which was also the earliest agricultural product traceability system. In 2002, the "Food Safety Law" compiled by the European Union came into effect. It is mandatory that companies related to 
food and feed operations must implement a traceability system, clarify the responsibilities of all relevant personnel, and ensure traceability from the production site to the dining table. In 2004, the European Union further introduced a trade control and expert system to strengthen and deepen the traceability of agricultural products. In addition, it also requires the use of the "Global Harmonized Code System" internally to facilitate consumers to trace product information in the traceability system. At present, the European Union has established a unified database to record in detail the entire process information of the tracked products. In 1996, the United Kingdom established the Livestock Tracking System (CTS) based on the Internet. France, the Netherlands, and Denmark have also established their own traceability systems after the United Kingdom to record and track the data information of the entire life cycle of livestock. Australia established the National Livestock Certification System (NLIS) in 2001 to track the entire process of domestic cattle from birth to death. In addition, it has also implemented the Australian Meat Standard (MSA) to strengthen the supervision of the middle links of the supply chain. Canada has implemented a mandatory labeling system for live cattle and beef products since 2002, and has also established its own national unified agricultural product traceability system standards. In 2002, the U.S. Congress promulgated the "Biological Anti-terrorism Act", which started the construction of a traceability system for agricultural product quality and safety. In 2004, the US FDA promulgated the "Food Safety Tracking Regulations", which clearly requires all companies involved in food circulation to establish and keep complete records of the entire circulation process. In 2009, the US Department of Agriculture created the "National Animal Identification System" (NAIS) project to track livestock and pastures in contact with foreign animal diseases. Japan began to promote the "food traceability system" in 2001, and most supermarkets have installed product traceability terminals, basically realizing the traceability of retail business in the food sector. In 2003, Japan began to trace beef products. In 2005, the Japanese Agricultural Cooperative Organization (referred to as the Agricultural Cooperative Organization) required that agricultural products that were circulated through the agricultural cooperative must be traceable. In 2008, Japan announced its plan to establish a traceability system for rice.

In 2004, the Ministry of Agriculture and Rural Affairs of China took the lead in piloting the traceability system in Beijing and Hebei, and implemented the "Pilot Project for the Traceability System of Vegetable Products in Beijing". On this basis, some large supermarkets in Beijing started the traceability system for vegetable products. Pilot. At the same time, other provinces and cities have also started pilot work on agricultural product traceability systems. In 2007, some first-tier cities took the initiative to introduce the agricultural product traceability system mechanism into the agricultural field. In the same year, the Article Coding Center launched the China Barcode Promotion Project, took the lead in pilot projects in Shanghai, Wuhan and other places, and also carried out lots of research on the policy of agricultural product traceability system. In 2008, the state took the initiative to establish and improve the labeling of agricultural products, and establish and implement a traceability system for agricultural product safety. In addition, there are also the establishment and trials of traceability systems such as the national vegetable quality and safety traceability system. In 2017, the national agricultural product quality and safety traceability management information platform was officially launched. The pilots were first launched in Sichuan, Guangdong, and Shandong, but the operation time was relatively short and the operation effect was not clear. In general, the construction of the international agricultural product quality traceability system is still in the development stage, and the domestic agricultural traceability system is still in its infancy. It lacks a unified quality information standard and cannot achieve cross-system query. More needs to be carried out. Research and practice.

Researchers at home and abroad are not only actively exploring the role of blockchain technology in promoting data sharing, ensuring information integrity, and traceability, but also the impact of blockchain on the operation of agricultural traceability systems and the impact on institutional management capabilities, etc. Research has been carried out on various topics. Researchers attach great 
importance to the role of blockchain technology in promoting data sharing and ensuring information security, and have launched a lot of practical research on this. Provenance is the first company to use blockchain technology to provide full traceability for products in the supply chain. It tracks the entire life cycle of the product. There are various products in the supply chain. Application research in the agricultural field is carried out. The pilot project of tuna certification based on blockchain technology, using supply chain technology to realize the transparency and traceability of data information on the supply chain. Ripe Technology applies blockchain technology and Internet of Things (Iot) technology to its company's management system, using Internet of Things technology to track the entire process of crops from planting, transportation to sales, and the content recorded through blockchain technology is very detailed And to be specific, ensure that the data cannot be tampered with. Including changes in crop appearance, color, and maturity. Each agricultural product has its own detailed record. In the new asset management system, the credibility, integrity, and sharing of data information have been greatly improved compared to the past. The management model of distributed accounting to ensure the authenticity and credibility of data also provides new development ideas for other farm managers. SkuChain company applies blockchain technology to the tracking link of the entire product circulation, and uses blockchain technology to track the entire circulation process of agricultural products, thereby strengthening the record and supervision of the product supply chain. By adopting the distributed accounting method, and through the form of data opening and sharing, users can query detailed information about the production date and production status of the purchased agricultural products anytime and anywhere. The integrity and transparency of data information in the supply chain provide a solid and credible foundation for the traceability of information. IBM cooperates with domestic and foreign research institutions such as Wal-Mart and Tsinghua University to use blockchain in the food information credible traceability system. Blockchain technology tracks and authenticates each product, and saves open and transparent data information, which greatly facilitates management. Food traceability has been achieved inside the supermarket. Whether it can be used on a large scale is still unknown. In the same year, Leng proposed a public blockchain system based on the dual-chain structure of the agricultural supply chain in response to some key problems existing in the current domestic public service platform, that is a blockchain based on the "user information chain" and the "transaction chain" system, and in-depth study of this double-chain structure and its storage mode. Practical results show that the agricultural product supply chain based on the dual-chain structure can ensure the openness and security of transaction information, while also effectively guaranteeing privacy and security, and efficiently completing tasks such as resource matching, thus increasing the public's trust in the public service platform. Proving that blockchain technology has huge application potential in the field of public utilities, or it can be applied to more large-scale fields.

Through the analysis and research of domestic and foreign blockchain traceability cases, it was found that only by truly realizing the traceability of the agricultural product supply chain that one can fundamentally resolve the food safety crisis. Traditional traceability has huge room for improvement in the safety, reliability and traceability of information, while the application of blockchain technology can improve the sustainability of the agricultural supply chain. The Blockchain technology will ensure the credibility, high transparency, integrity and openness of data information in all links of the supply chain, and effectively solve the shortcomings of traditional technology traceability systems in data storage, credibility, sharing and security and promote the more stable development of the domestic agricultural product market.From the above analysis, it can be seen that after blockchain technology is currently used in the field of of agricultural product traceability, the following functions can be achieved:

1) The source can be checked. All production raw material information is collected, recorded and tracked, realizing the full life cycle management of product supply links, production links, circulation links, sales links, and service links. 
2) Whereabouts can be traced. Each item has unique code, thus, the whole process of tracing the product circulation process is easy.

3) Responsibility can be investigated. One thing to one code, once the product has a problem, you can accurately find out which link is the problem and who is the responsible person.

4) Information visualization. A series of information about the product's brand, name, manufacturer, and specifications can be checked by consumers by scanning the QR code to enhance the credibility of the brand.

5) Big data management. With the help of one item, one code, companies can directly introduce participating consumers into the company's data platform, continuously improve the personalized interaction between the company and consumers, and enhance consumers' loyalty and stickiness to the brand.

\section{Conclusions}

While discovering that blockchain technology has brought innovation to agricultural traceability, the researchers also discovered existing problems. Based on the inherent technical shortcomings of the blockchain technology itself, as well as the block capacity and 51\% attack issues and industry standard issues, this article makes several suggestions:

1) According to the development and application of blockchain, the current technology and application are not very mature, the relevant national scientific research departments should increase capital investment and research on artificial intelligence, blockchain and other technologies, strengthen the research and development of the underlying technology, and broaden the practice, and gradually break through technical limitations such as insufficient capacity and slow processing speed. In addition to national scientific research institutions, large-scale industrial and commercial enterprises and agricultural institutions in the agricultural field should also actively join the ranks of blockchain research and development. The specific method of joining can refer to the three strategies of large international banks to participate in blockchain research and development. These three strategies are simply that companies with strong capital and sufficient talents can learn from the practice of the Bank of New York Mellon, which is to establish an internal blockchain technology research and development laboratory, and companies that do not want to increase internal management pressure can follow the Goldman Sachs investment zone. Blockchain startups can also learn from Commonwealth Bank of Australia and cooperate with blockchain startups.

2) It is necessary to vigorously develop the construction of communication infrastructure in the vast rural areas and western regions. To speed up the process of agricultural informatization, one must first establish an Internet-based information platform and form a complete network system. This requires financial support from the state, as well as policy guidance, manpower arrangements, and organization and coordination from government departments.

3) Speed up the cultivation of high-quality agricultural practitioners. On the one hand, it is necessary to carry out publicity, education and regular training on information technology such as blockchain to grassroots agricultural practitioners, to improve the information knowledge reserve, information awareness and use of information of grassroots agricultural staff, and increase grassroots agricultural staff to participate in the block. There should be enthusiasm and confidence in chain applications. On the other hand, considering that blockchain technology is an integrated technology produced by the innovative combination of multiple information technologies, scientific research institutions and education departments should correspondingly increase their understanding of interdisciplinary, strong sense of innovation, proficient in information technology, and familiarity with agriculture. There should be cultivation of scientific research talents with the laws of economic operation. 
4) The judicial department should formulate more complete laws and regulations on agricultural product safety traceability and blockchain application to strengthen the supervision of all links in the food chain and prevent the improper use of blockchain technology from causing serious privacy leaks. The Ministry of Agriculture and Rural Affairs and other relevant agencies will also issue detailed guidance policies, white papers and other documents on the application of blockchain in the agricultural field in real time to give relevant companies and practitioners the most timely and authoritative guidance to prevent the abuse of technology from causing market chaos.

5) It is recommended that the state guide and encourage the construction of blockchain industry standards, so that more and more government departments, industry associations, companies and individual organizations will participate in the development trend of the blockchain industry. Industry standards can greatly promote the development of the industry and reduce costs.

\section{Acknowledgement}

This thesis was written by the 2021 Sehan University Sabbatical Program.

\section{References}

[1] H. S. Yan, H. H. Kim, J. W. Yang, Efficiency Analysis of Chinese Blockchain Concept Stock Listed Companies, International Journal of Advanced Smart Convergence, (2020), Vol.9, No.3, pp.17-27, DOI: http://dx.doi.org/10.7236/IJASC.2020.9.3.17

[2] S. J. Han, S. Lee, D. Lee, S. Y. Park, An Experimental Study For Access Control System In Public Blockchain, The The Journal of the Institute of Internet, Broadcasting and Communication, (2020), Vol.20, No.1, pp.55-60, DOI: https://doi.org/10.7236/JIIBC.2020.20.1.55

[3] D. Q. Sun, Y. Zhuang, N. L. Sun, Application of Blockchain Technology in Agriculture, Agricultural Technology and Equipment, (2020), Vol.2, No.36, pp.40-65, DOI: 10.3969/j.issn.1673- 887X.2020.02.032

[4] C. Wang, Blockchain-based Insurance Industry Information System Architecture and Key Technology Research, China Academy of Railway Sciences, Doctoral Dissertation, (2017)

[5] H. C. Jiang, H. Y. Zhao, W. Ge, Analysis of China's Tea Industry Status and Development Trend, China Agricultural Resources and Regionalization, (2009), Vol.3, No.5, pp.67-98, DOI: CNKI:SUN:ZGNZ.0.2009-03-005

[6] H. J. Wang, A. L. Zhou, X. H. Liang, Research on the application of blockchain technology in the field of traceability of agricultural products, China Agricultural Science, (2020), Vol.36, No.3, pp.158-164, DOI: https://kns.cnki.net/KCMS/detail/detail.aspx?dbcode=CJFD\&filename=ZNTB202036026

[7] J. P. Qian, W. B. Wu, P. Yang, A review of the impact of a new generation of information technology on the intelligence of agricultural product traceability systems, Chinese Journal of Agricultural Engineering, (2020), Vol.5, No.4, pp.182-191, DOI: CNKI:SUN:NYGU.0.2020-05-021

[8] Z. Wang, Research and Realization of the Application of Blockchain Technology for Anti-tampering in the Traceability Information of Edible Agricultural Products, Nanchang University, Doctoral Dissertation, (2020)

[9] W. H. Gao, L. Shi, Design of Enterprise Informatization Data Traceability Platform Based on Blockchain Technology, Information and Computer, (2020), Vol.3, No.2, pp.67-69, DOI: CNKI:SUN:XXDL.0.2020-03-024

[10] Z. Wang, Z. Q. Liang, Y. L. Zheng, The application of the intersection of semantic web technology and blockchain technology in the field of agricultural product quality and safety traceability, Agricultural Library and Information, (2019), Vol.1, No.2, pp.60-68, DOI: 10.13998/j.cnki.issn1002-1248.2019.01.007

[11] K. Leng, Y. Bi, L. Jing, H.-C. Fu, I. V. Nieuwenhuyse, Research on agricultural supplychain system with double chain architecture based on blockchain technology, Future Generation Computer Systems, (2018), Vol.86, No.18, pp.641-649, DOI: https://doi.org/10.1016/j.future.2018.04.061 
[12] N. Ding, X. T. Zhu, The evolution of blockchain technology and the prospect of industrial application, Information Security Research, (2017), Vol.3, No.8, pp.200-210, DOI: 10.3969/j.issn.2096-1057.2017.03.002

[13] Y. Y. Cai, L. Ye, C. J. Lin, Electronic agriculture blockchain and digital agricultural democratization theory and application, Journal of Cleaner Production, (2020), Vol.268, No.20, pp.71-122, DOI: https://doi.org/10.1016/ j.jclepro.2020.122071

[14] H. Lei, U. Israr, D.-H. Kim, A secure fish farm platform based on blockchain for agriculture data integrity, Computers and Electronics in Agriculture, (2020), Vol.170, No.3, p.105251, DOI: https://doi.org/10.1016/ j.compag.2020.105251

[15] W. Zhao, Research on Agricultural Food Safety Traceability System Based on Blockchain Technology, Technology Economics and Management Research, (2019), Vol.11, No.08, pp.20-55, DOI: CNKI:SUN:JXJG.0.2019-01-003 